\title{
On the Self-Studying in Higher Mathematics
}

\author{
Xiaoying Sun \\ NanChang Institute of Science \& Technology,Nanchang,330108
}

\author{
Keyword: Higher mathematics; Self-study; Undergraduates
}

\begin{abstract}
In the circumstance of the age of knowledge economy and society of information, the update of knowledge have sped up its frequency, which make it of vital importance to train college students' abilities to self-study, innovate, and to cultivate their ideas of lifelong learning. Self-studying is an essential part in the curriculum revolution of basic education in our country, which orientates the trend of revolution and developing of education worldwide. But some problems occurred and still to be solved in the practice, the starting point of this essay is how we can form effective strategies in order to solve these problems. In this essay, the status quo of researches at home and abroad on self-studying and the ability to self-study is analyzed, based on the background of the idea of self-studying in higher mathematics being raised up. It also come up with the idea that we should cultivate students' ability to self-study in the teaching process of higher mathematics, by combining the current situation of higher mathematics education and the final purpose of teaching together.
\end{abstract}

\section{Introduction}

The 21st century is an age of knowledge economy, and the update of knowledge in the 21st century refreshes rapidly. Under this circumstances, the lifelong learning is emphasized more. The new era calls for a new generation who are healthy physically and mentally, and own the ability of lifelong study, which requires the education of higher mathematics should focus on training undergraduates' learning abilities, especially the ability to lifelong study and the sense of lifelong mathematics learning. The sine qua non of achieving it is the enhancement of ability to self-study.

This essay provides the basic strategies for improving the self-studying in higher mathematics with the base of the background that the idea of self-studying in higher mathematics being raised up. In this essay, the significance of studying motivation and interest cultivation in the teaching process of higher mathematics is emphasized. The teaching methods of higher mathematics should be refined, it should lead students to study by themselves. The teaching idea in maths class should be refreshed, in order to offer students the best atmosphere of self-studying. Class questions should be asked in corresponding situations, which helps students to study positively. Teachers are supposed to teach the methods and strategies of learning mathematics to students, leading them to study by themselves, to strengthen mathematics modeling, and to solve practical problems. Maths teachers must shift their ideas and the traditional teaching approaches. What they should do is promoting the development of students by using the method of commenting appropriately.

\section{The Meaning of Researching the Self-studying in Higher Mathematics}

The inside motivation for students to study by themselves is teachers' leading in teaching process. Teachers should use various and flexible teaching methods to encourage them to study by themselves according to the characteristics and status quo of undergraduates' studying, to create multiple opportunities that guide them to self-study positively, and to improve their scores and enhance their wishes and abilities to lifelong study eventually. In this way, everyone's abilities to self-study can be developed adequately.

By researching on self-studying in higher mathematics, we have known the current situation of undergraduates' higher mathematics studying, and we've also understood the importance of variables which are related to self-study in higher mathematics. By analyzing the data of variables of self-study in higher mathematics, we've found the key problems that trouble undergraduates, and solve them gradually 
with pertinence in the process of teaching higher mathematics. The meaning of this research is cultivating the undergraduates' ability to self-study, and encouraging them to take control of their study activities. When the undergraduates are improving their subjective initiatives and innovative spirits, their teachers are getting to recognize students' key role in studying as well, and they will guide students to master scientific learning skills and help them to make feedbacks in study and correct bad learning habits in time, so that their comprehensive quality and innovative skills will be improved.

\section{The Deficiencies of Researches on Self-study in Higher Mathematics in China}

Although the researches on self-study in our country have come into a unprecedented prosperous period, and have received abundant fruits, the deficiencies and problems still exist, and showed mainly in the following aspects:

Firstly, the researches on self-study mostly focus on students from primary and middle schools, the research for undergraduates take only a small part. Face with the requirements of comprehensive quality from the new 21st century, we need to regard the self-studying cultivation for modern undergraduates as an aim or goal of education, but not a kind of process or mean.

Secondly, the tool for evaluation is not perfect, localized or of practicability. Therefore, it's necessary to dig and improve researches on self-study in China, particularly for the theory of evaluations of self-study, and the practical counterpart. We need to explore and discover a scientific mode of self-study in the education for all-round development, and then make a tool for self-study evaluation which is practical and localized, making it an excellent servant for training people who are of high qualities and good prospects.

Thirdly, researches on self-study involves in fields of Chinese, foreign languages, lower mathematics teaching and so on, and it barely involved in the high educational teaching, especially the higher mathematics. Therefore, as a worker in high mathematics field, I feel obliged to do more researches on this subject, to adjust to the new demand raised by new age.

\section{Basic Strategies for Improving the Self-studying in Higher Mathematics}

We've come up with some strategies for undergraduates to improve their ability to self-study in higher mathematics by analyzing the current situation and the effect, after looking through plenty of bibliographies.

Motivating Them, and Cultivating Them. The motivation is the premise and fundament of carrying out studying activities. Only with strong motivation for studying, can students study the higher mathematics positively, and achieve a better grade, which can be a new motivation for them to study harder. Students will gain numerous motivations if we arouse their motivation for learning mathematics and cultivate their interests to knowledge. Transferring their attitude from "people want me to learn" to "I want to learn". The interests of learning higher mathematics is the important fundament for them to self-study, and a catalyze to improve the level of self-study.

Helping then to Set Scientific Learning Goal of Higher Mathematics. The set of learning goal is an important part in the process of self-study, and it have the functions of orientation, adjustment, maintenance, and evaluation. Therefore, whether a student can set a mathematics learning goal for himself or herself is of vital importance for him or her to study mathematics by self. In general, self-studying students prefer to set specific, short-term, challenging but still feasible goal, which will help the others as well if we assist them to set.

Conducting "Variable Teaching", Cultivating Flexible Thinking. Thinking flexibility means one can analyze specific questions and adjust oneself when the situation changes, and can use learnt knowledge skillfully to solve problems. "Variable teaching" means teachers can quote textbook flexibly, use teaching methods which can train the reactionary ability of students, such as a question, several answers, and various questions. It can used to cultivate students' flexibility.

For example, evaluating 


$$
\left|\begin{array}{ccccc}
0 & \mathrm{a} & \mathrm{a} & \ldots & \mathrm{a} \\
\mathrm{a} & 0 & \mathrm{a} & \ldots & 0 \\
\mathrm{a} & \mathrm{a} & 0 & \ldots & \mathrm{a} \\
\ldots & \ldots & \ldots & \ldots & \ldots \\
\mathrm{a} & \mathrm{a} & \mathrm{a} & \ldots & 0
\end{array}\right|
$$

After students figuring it out, we will change it as following:

A. Transferring " 0 " in the determinant into " 1 "; B. Transferring " 0 " in the lower middle into " $x$ "; C. Transferring "a" in the lower middle into "-a"; D. Transferring B. into

$$
\left|\begin{array}{ccccc}
a_{1}+x & a_{2} & a_{3} & \cdots & a_{n} \\
a_{1} & a_{2}+x & a_{3} & \cdots & a_{n} \\
\cdots & \ldots & \ldots & \cdots & \ldots \\
a_{1} & a_{2} & a_{3} & \ldots & a_{n}+x
\end{array}\right|
$$

These transfers motivate students' thinking, and cultivate their flexibility. They are very interested and get into status of self-study quickly.

Conducting "Exploring Teaching", Cultivating Students' Wide and Unique Thinking .The wide thinking means one can think about a question from multiple angles, and raise various solutions for it. It's a quality of using a theory on different fields to solve problems. The unique thinking means one can use unusual way and thinking to the questions to be solved. The "exploring teaching" means a teaching method by which teachers guide students to explore by themselves about a question, reaching out their own solutions eventually, such as various solution for one question, which enables students to think from different angle, and achieve different solutions in the end. Also, they can compare and find out the best solution. The exploring teaching methods can be used to cultivate the wide and unique thinking of students.

\section{Conclusion}

The achievement of self-studying is both one of the requirements of the quality-oriented education, and the requirement of wholesome development of students. Students practice, think, discover and innovate by themselves and their ability and motivation are used, in this way, showed their key role in studying. The gain of self-study is a process of transferring outside studying skills to inside motivation. The cultivation of self-studying should be carried on in learning activities. There're two premises for conducting self-studying: students acquiring ability to learn and schools offering space for self-studying. The former is subjective condition and the latter is objective one, which is providing students with selecting-free materials, spaces, methods and other facilities.

The sponsor: The Project of Science, Ministry of Education in Jiangxi province (The code: GJJ151244)

\section{References}

[1] Zhang X, Yang Y, Bao B. Task Decomposition and Grouping for Customer Collaboration in Product Development[J]. Journal of Intelligent Systems, 2016, 25(3):361-375.

[2] Ghaffarkhah A, Mostofi Y. Dynamic Networked Coverage of Time-Varying Environments in the Presence of Fading Communication Channels[M]. ACM, 2014.

[3] Smith K W. KWSnet Robots/Robotics Index[J]. Kwsnet, 2015.

[4] A case study of a micro-manufacturing process[J]. Computers in Industry, 2015， 74(C):135-150.

[5] Ding L, Shi H. Design and practice of network teaching and evaluation model of Advanced Mathematics[J]. Journal of Shenyang Normal University,2016.

[6] P. Gaikwad D, C. Thool R. A Framework for Simulation of Intrusion Detection System using Support Vector Machine[J]. International Journal of Computer Applications, 2014, 76(2):23-30.

[7] Databases O. Computer Science Conference Rankings[J]. 2016.

[8] Urbański M. Countable Alphabet Non-autonomous Self-affine Sets[J]. 2014, 92:129-145. 
[9] Georgiou H V. Games People Play: an Overview of Strategic Decision-Making Theory in Conflict Situations[J]. 2015.

[10] Murray J. Murray and Metz Manuscript for Grad Student Symposium[J]. 2015.

[11] Xu P, Su X, Mahadevan S, et al. A non-parametric method to determine basic probability assignment for classification problems[J]. Applied Intelligence, 2014, 41(3):681-693.

[12] Nobukawa S, Nishimura H, Yamanishi T, et al. Chaotic States Induced By Resetting Process In Izhikevich Neuron Model[J]. Journal of Artificial Intelligence \& Soft Computing Research, 2015, 5(2):109-119. 